\title{
Incidence and risk factors of post operative delirium in elderly patients who underwent spinal anesthesia in Orotta, Halibet and Sembel Hospitals: A Cross sectional analytic study in ERITREA
}

Michael Beraki Mengistu ( $\square$ mikoberaki88@gmail.com )

University of Asmara https://orcid.org/0000-0002-4958-1876

Yonatan Mehari Andemeskel

Asmara College of Health Sciences

Ariam Tsegay Emehatsion

Asmara College of Health Sciences

Habtom Tareke Wrieta

Asmara College of Health Sciences

Natsnet Yacob Gebreyessus

Asmara College of Health Sciences

Research article

Keywords: delirium, elderly, postoperative delirium, spinal anesthesia

Posted Date: December 26th, 2019

DOI: https://doi.org/10.21203/rs.2.19630/v1

License: (c) (1) This work is licensed under a Creative Commons Attribution 4.0 International License.

Read Full License

Version of Record: A version of this preprint was published at Journal of Surgery \& Anesthesia Research on March 31st, 2021. See the published version at https://doi.org/10.47363/JSAR/2021(2)116. 


\section{Abstract}

\section{Background}

Delirium is a common but often underdiagnosed set of transient symptomin the elderly patients following surgeries under spinal anesthesia. Delirium can be improved with early recognition and diagnosis based on the established standard criteria. The identification of the possible contributing factors and magnitude of the burden will help in the management of the fragile elderly patients. Managing delirium with environmental, supportive and pharmacological interventions will possibly reduce the incidence, and complication associated with postoperative delirium. The aim of this study is to determine the incidence of postoperative delirium and associated risk factors in elderly patients who did surgery under spinal anesthesia.

Method

This cross sectional study was conducted in the National Referral Hospitals in Eritrea (Orotta and Halibet), including Sembel hospital from February to May, 2019. The study participants were elderly patients (age $\geq 65$ years) having no mental disorder, no history of acute cerebrovascular disease, no known history of delirium and/or dementia. Basic background and clinical characteristics of the patients was collected. To assess the status of cognitive impairment level, the Mini Mental State Examination and Confusion Assessment Method tools were used. Data was collected through an interview method. After the data was entered into SPSS version 22 software, it was conducted with frequency, percentage, bivariate and multivariate logistic regression analysis method as appropriate. $P$ value at $<0.05$ was considered as statistically significant.

Conclusion

Postoperative delirium occurred in 14 out of 129 case $(10.9 \%)$. The multivariate analysis showed that only age was significantly associated with postoperative delirium. The other variables did not significantly influence the occurrence of POD. Therefore, $t$ he incidence of postoperative delirium after spinal anesthesia was relatively high (10.9\%). Similarly, old age was found as the risk factor for the development of delirium in those elderly patients who underwent spinal anesthesia. This findings might help to develop preventive strategies to decrease POD through targeted factors.

\section{Background}

Post-Operative Delirium is one of the most common complication following surgery and anesthesia in elderly patients (Ozbas et al., 2018). As elderly are easily vulnerable to many surgical complications, meticulous assessment and observations of such individuals is highly crucial. It is increasingly evident that delirium in elderly is associated with poor outcome and increased health care costs. So, its early diagnosis is crucial to prevent patients from developing severe long-lasting complications. Unfortunately, 
only a fraction of patients with delirium are quickly recognized by care-givers (Whitlock, Vannucci, \& Avidan, 2011).

POD is a form of delirium that manifests in patients who have undergone surgical procedures and anesthesia, usually peaking between one and three days after their operation. It must be differentiated from emergency delirium which occurs in $8-20 \%$ of patients after awakening from General anesthesia, especially in younger ages (Radtke, et al., 2010).

The causes of the possibility of a relationship among emergence delirium, POD, postoperative cognitive decline and postoperative incident dementia have not yet been fully clarified (Whitlock et al., 2011).

The pathogenesis of delirium remains to be elucidated, but it has been associated with abnormal neurotransmitter levels (particularly acetylcholine and dopamine), slowing of cortical electrical activity, and inflammatory change in blood -brain barrier permeability, abnormal melatonin metabolism and hypothalamic- pituitary - adrenal axis disturbance. Patients with delirium usually present the hyperactive form of delirium, commonly characterized by restlessness, agitation, hallucinations and delusions. In contrast the hypoactive form of delirium, characterized by reduced movement, paucity of speech, and unresponsiveness, can be misdiagnosed as depression, anxiety or even as a calm and comfortable patient when proper screening is not performed. A rough distribution of delirium presentations suggest that it may be of the hyperactive form in $25 \%$, hypoactive in $50 \%$ and mixed in $25 \%$ of cases (Ansaloni, Catena, Chattat, \& Fortuna, 2010). The more clinically "silent" hypoactive type may be associated with greater mortality than hyperactive types.

Elderly surgical patients frequently experience POD and the sub sequent development of POCD (Androsova, Krause, Winterer, \& Schneider, 2015).“Delirium is also a neuro-inflammatory condition characterized by disturbance in attention (that is reduced ability to direct, focus, sustain and shift attention), disturbance in awareness (i.e. reduced orientation to the environment"(Fitzpatrick \& Owen, 2018). It develops over a short period of time but tends to fluctuate and it also shows disturbance in cognitive which is memory deficient, disorientation, language, visuospatial ability, or perception.

Delirium is common in hospitalized patients with the incidence ranging from $14 \%$ on general medical ward to $82 \%$ in the intensive care unit (Inouye, Westendorp, \& Saczynski, 2013). Prevalence of delirium varies between $14 \%$ and $56 \%$ for inpatient while the range goes up to $20-79 \%$ for elderly patients (Ozbas et al., 2018). Although it is common, it is not recognized in $64-84 \%$ patients and not diagnosed in $33.63 \%$ (Yasayacak \& Eker, 2012).

The incidence of POD depends on type of surgery, type of anesthesia, preoperative hypoxia, hypoalbuminemia, low serum sodium, potassium, glucose or blood sugar level.(Rudolph et al., 2008) The prevalence of POD is associated with higher mortality, increased incidence of postoperative complication, longer duration of hospital stay, greater utilization of social financial assistance and earlier retirement (Green et al, 2009; Robinson et al, 2009; Steinmetz et al, 2009; Ansaloni et al, 2010; Lui et al, 2013). 
Delirium is preventable in $30-40 \%$ of case (Inouye, Westendorp, \& Saczynski, 2013), and this holds substantial public health relevance as a target for intervention to prevent the associated burden of downstream complications and costs. Accordingly, delirium has been increasingly used as an indicator of health-care quality for elderly people (Inouye, Westendorp, \& Saczynski, 2013).

Therefore the purpose of this paper is to assess the incidence and magnitude of POD among elderly patients undergoing surgeries under spinal anesthesia and to identify factors affecting its occurrence.

\section{Method}

\section{Study Design}

A descriptive cross sectional study design was used to determine the incidence and risk factors of POD in elderly patients after spinal anesthesia. The study was conducted in Asmara, the capital city of Eritrea. There are two National Referral Hospitals which provides medical and surgical service to the patients. The surgical departments of those hospitals have General, Gynecology, Maternity, Orthopedic and Burn wards which provides service to all age groups. In addition, there is another private Hospital which is engaged in similar service. The study was conducted in all these hospitals, namely, Orotta and Halibet medical surgical National Referral Governmental Hospitals and Sembel Private Hospital.

\section{Study population}

Total enumeration of the participants on the specific period was used. All 65 years of age \& above elderly patients who underwent any type of surgery under spinal anaesthesia during the study period were included in the study.

\section{Selection Criteria}

\section{Inclusion Criteria}

- All volunteer elderly patients who were scheduled for elective surgery undergo spinal anaesthesia.

\section{Exclusion criteria}

- Age below 65 years,

- Patients who declined to participate in the study,

- Preoperative history of dementia (e.g. Alzheimer disease), psychosis (e.g. schizophrenia), cerebral vascular disease, brain surgery, traumatic brain injury.

- Patient who had hemodynamic instability, 
- ASA classification > II,

- Patient with serious renal insufficiency who underwent dialysis before surgery and serious hepatic insufficiency,

- Patient with history of alcohol abuse,

- Communication and listening impairment.

\section{Study Variables}

\section{Socio-demographic variables}

- Age, gender, marital status, occupational status, and educational status.

\section{Clinical variables}

- Type of surgery, drug administered intraoperative, intensity of pain, duration of surgery, ASA classification, blood loss, and preoperative MMSE score.

\section{Research variable}

- Postoperative delirium

\section{Data collection techniques}

After permission was sought from OCMHS and $\mathrm{MOH}$ scientific research and ethical committee, a written informed consent was taken from each participant. Then an interview was conducted to document pertinent patient Scio-demographic and clinical characteristics. Preoperative cognitive status was scored using MMSE tool to identify if there is any cognitive impairment. The presence and severity of POD among patients was then evaluated using CAM tool during the postoperative $1^{\text {st }}, 2^{\text {nd }}$ and $3^{\text {rd }}$ days after surgery. During the data collection process regarding the CAM assessment the nurses in duty and their relatives were also involved to document if any unusual behaviour of the participants was seen after the surgery that has a similar explanation about delirium in CAM score. At the same time, the intensity of pain was measured when the participants was evaluated for delirium postoperatively using VAS tool. All the data collectors were the researchers themselves.

\section{Statistical analysis}

Data was entered into Statistical Package for Social Sciences (SPSS, version 22). Preliminary cleaning of the entered data was performed before the analysis. Descriptive analysis for categorical variables was 
performed using frequency and percent. Summary result for continuous variables was done using mean (SD) after checking normality of the data. Incidence rate of delirium was computed and potential risk factors was identified using bivariate logistic regression. Variables with $p$-value $<0.05$ at bivariate level was further be analyzed at multivariate level. Both Crude odds ratio (COR, 95\% $\mathrm{Cl}$ ) and Adjusted odds ratio $(A O R, 95 \% \mathrm{Cl})$ were reported. Tables and figures were used to present the results. P-values less than 0.05 was considered as significant in all the analyses.

\section{Results}

\section{Population Characteristics}

In this study, a total of 155 participants were selected to participate in the study. Out of these 16 participants who didn't fulfill the inclusion criteria were excluded and the rest 139 were willing and gave their consent for the interview to be done. And out of these, six participants were early discharged and four participants were changed to general anesthesia.

As it is indicated in Table 1, majority of the participants 102 (79.1\%) were males and the remaining $27(20.9 \%)$ were females. The Mean age of the participants was 74 (SD \pm 6.62$)$. Most of the participants were married covering $94(72.9 \%)$ and concerning their educational status, 52(40.3\%) were illiterate, and only $19(14.7 \%)$ were secondary and above, and the remaining $58(45 \%)$ participants were elementary \& junior. Majority of the participants were employed, in which self-employed comprises $45(34.9 \%)$ and employed 30 (23.3\%). The rest of participants were unemployed 54 (41.9\%). 
Table 1

Socio-demographic characteristics of the patients

\begin{tabular}{|c|c|c|c|}
\hline Variables & & Frequency & Percentage \\
\hline \multirow[t]{3}{*}{ Age $($ mean $=74, S D= \pm 6.62)$} & $65-74$ & 71 & 55 \\
\hline & $75-84$ & 49 & 38 \\
\hline & $\geq 85$ & 9 & 7 \\
\hline \multirow[t]{2}{*}{ Gender } & Male & 102 & 79.1 \\
\hline & Female & 27 & 20.9 \\
\hline \multirow[t]{4}{*}{ Marital status } & Married & 94 & 72.9 \\
\hline & Single & 1 & 0.8 \\
\hline & Divorced & 8 & 6.2 \\
\hline & Widowed & 26 & 20.2 \\
\hline \multirow[t]{3}{*}{ Educational status } & Illiterate & 52 & 40.3 \\
\hline & Elementary \& Junior & 58 & 45 \\
\hline & Secondary \& above & 19 & 14.7 \\
\hline \multirow[t]{3}{*}{ Occupational status } & Employed & 30 & 23.3 \\
\hline & Self employed & 45 & 34.9 \\
\hline & Unemployed & 54 & 41.9 \\
\hline
\end{tabular}

Regarding their clinical characteristics, those who did urologic surgery were the most covering 52(40.3\%) $\&$ following by those who did orthopedic surgery $48(37.2 \%)$ surgeries. The time of surgery took to be done was also considered and $85(65.9 \%)$ were completed in less than one hour \& the rest $44(34.1 \%)$ were completed between one \& two hours and most participants were ASA class I, 98(76\%). Concerning the status of postoperative pain scored during the study period, No pain score was in 64(49.6\%), severe pain score was in $1(0.8)$, the remaining showed mild $46(35.7 \%)$ \& moderate pain $18(14 \%)$ scores. Regarding the drug administered during the intraoperative period, only $2(1.6 \%)$ patients were given analgesic drugs (fentanyl and pethidine) and 6(4.7\%) patients were given benzodiazepine (midazolam and diazepam). Majority of the patients, 125(96.9\%) experienced less than $2000 \mathrm{ml}$ blood loss (Table 4.2). 
Table 2

Clinical characteristics of the patients

\begin{tabular}{|c|c|c|c|}
\hline Variables & & Frequency & Percentage \\
\hline \multirow[t]{4}{*}{ Type of surgery } & Orthopedic & 48 & 37.2 \\
\hline & Hernia surgery & 13 & 10.1 \\
\hline & Urology & 52 & 40.3 \\
\hline & Others & 16 & 12.4 \\
\hline \multirow[t]{2}{*}{ Duration of surgery } & $<$ one hour & 85 & 65.9 \\
\hline & one upto two hour & 44 & 34.1 \\
\hline \multirow[t]{2}{*}{ ASA classification } & Class I & 98 & 76 \\
\hline & Class II & 31 & 24 \\
\hline \multirow[t]{4}{*}{ Postoperative pain } & No pain & 64 & 49.6 \\
\hline & Mild pain & 46 & 35.7 \\
\hline & Moderate pain & 18 & 14 \\
\hline & Severe pain & 1 & 0.8 \\
\hline \multirow[t]{3}{*}{ Drug administered } & Analgesia & 2 & 1.6 \\
\hline & Benzodiazepine & 6 & 4.7 \\
\hline & None & 121 & 93.8 \\
\hline \multirow[t]{3}{*}{ Analgesia } & Fentanyl & 1 & 0.8 \\
\hline & Pethidin & 1 & 0.8 \\
\hline & None & 127 & 98.4 \\
\hline Hypnotics & None & 129 & 100 \\
\hline Benzodiazepine & Midazolam & 6 & 4.7 \\
\hline
\end{tabular}




\begin{tabular}{|llll|}
\hline Variables & & Frequency & Percentage \\
\hline & Diazepam & 1 & 0.8 \\
\hline None & 122 & 94.6 \\
\hline Blood loss & & & \\
& $<2000 \mathrm{ml}$ & 125 & 96.9 \\
\hline
\end{tabular}

\section{Preoperative Cognitive impairment level}

The participants were assessed for any cognition impairment preoperatively using MMSE score. Majority of the participants, $99(76.7 \%)$ were within the normal cognition score of MMSE. The remaining were categorized in to mild, moderate and severe cognition with $22(17.1 \%), 7(5.4 \%)$ and $1(0.8 \%)$, respectively (Table 3).

Table 3

Preoperative MMSE (Mini-mental state examination) score

\begin{tabular}{|llll|}
\hline Variables & & Frequency & Percentage \\
\hline MMSE score & Normal cognition & 99 & 76.7 \\
& Mild cognition & 22 & 17.1 \\
& Moderate cognition & 7 & 5.4 \\
& Severe cognition & 1 & 0.8 \\
\hline
\end{tabular}

\section{Incidence of Postoperative Delirium}

Participants were observed in the first, second and third postoperative days and out of the 129 participants, $14(10.9 \%)$ were found with delirium and the remaining $115(89.1 \%)$ did not show any sign of delirium (Fig. 1).

\section{Associates of postoperative delirium}

The results of the logistic analysis performed to identify the possible association between different variables and postoperative delirium at bivariate level is shown in Table 4. At bivariate level, age, educational level, marital status, POP, and cognitive impairment status were found to be significant associated with incidence of delirium. For unit increase in age, the odds of delirium was found to increase 
by $1.19(p<0.001)$. The odds of delirium among illiterate was 4.92 times more than those who were elementary and junior $(p=0.020)$. 
Table 4

Association of post-operative delirium with socio-demographic and clinical variables at bivariate level

\begin{tabular}{|c|c|c|c|c|}
\hline \multirow[t]{2}{*}{ Variables } & & \multicolumn{2}{|l|}{ Delirium } & \multirow[t]{2}{*}{ COR $(95 \% \mathrm{Cl})$} \\
\hline & & Non(\%) & Yes n(\%) & \\
\hline Age & & & & $1.19(1.08,1.31)$ \\
\hline \multicolumn{5}{|l|}{ Gender } \\
\hline & Male & $90(90.0)$ & $10(10.0)$ & Reference \\
\hline & Female & $25(86.2)$ & $4(13.8)$ & $1.44(0.42,4.98)$ \\
\hline \multicolumn{5}{|l|}{ E/Status } \\
\hline & Elementary \& Junior & $55(94.8)$ & $3(5.2)$ & Reference \\
\hline & Illiterate & $41(78.8)$ & $11(21.2)$ & $4.92(1.19,18.77)$ \\
\hline & Secondary \& above & $19(100)$ & $0(0.0)$ & * \\
\hline \multicolumn{5}{|c|}{ Marital Status } \\
\hline & Married & $88(93.6)$ & $6(6.4)$ & Reference \\
\hline & Single & $27(77.1)$ & $8(22.9)$ & $4.35(1.39,13.63)$ \\
\hline \multicolumn{5}{|c|}{ Occupation } \\
\hline & Unemployed & $46(85.2)$ & $8(14.8)$ & Reference \\
\hline & Employed & $29(96.7)$ & $1(3.3)$ & $0.20(0.02,1.67)$ \\
\hline & Self Employed & $40(88.9)$ & $5(11.1)$ & $0.72(0.22,2.37)$ \\
\hline \multicolumn{5}{|c|}{ surgery Type } \\
\hline & Others & $15(93.8)$ & $1(6.3)$ & Reference \\
\hline & Orthopedic & $38(79.2)$ & $10(20.8)$ & $3.95(0.46,33.58)$ \\
\hline & Hernia & $13(100)$ & $0(0.0)$ & * \\
\hline & Urology & $49(94.2)$ & $3(5.8)$ & $0.92(0.09,9.50)$ \\
\hline \multicolumn{5}{|c|}{ Surgery Duration } \\
\hline & Less than 1 hour & 73 (85.9) & $12(14.1)$ & Reference \\
\hline & 1 to 2 hours & $42(95.5)$ & $2(4.5)$ & $0.29(0.06 .1 .36)$ \\
\hline
\end{tabular}




\begin{tabular}{|lllll|}
\hline Variables & & Delirium & \multirow{2}{*}{ COR (95\% Cl) } \\
\cline { 2 - 4 } & & Non(\%) & Yes n(\%) & \\
\hline & Class II & $26(83.9)$ & $5(16.1)$ & Reference \\
\hline & Class I & $89(90.8)$ & $9(9.2)$ & $0.53(0.16 .1 .71)$ \\
\hline POP & & & \\
\hline & Moderate to severe & $15(78.9)$ & $4(21.1)$ & Reference \\
\hline & Mild Pain & $45(97.8)$ & $1(2.2)$ & $0.08(0.01,0.81)$ \\
\hline Drug Administered & No pain & $55(85.9)$ & $9(14.1)$ & $0.61(0.17 .2 .27)$ \\
\hline & Yes & & \\
\hline & No & $8(88.9)$ & $1(11.1)$ & Reference \\
\hline Cognitive Impairment & & $107(89.2)$ & $13(10.8)$ & $0.97(0.11,8.40)$ \\
\hline & Normal & & & \\
\hline & Mild & $94(94.9)$ & $5(5.1)$ & Reference \\
\hline & Moderate to severe & $4(50.0)$ & $4(50.0)$ & $18.80(3.60,98.11)$ \\
\hline
\end{tabular}

\section{Predictors of postoperative delirium}

The full multivariate logistic regression model showed that only age was found to be a significant predictor of postoperative delirium ( $\mathrm{AOR}=1.15,95 \% \mathrm{Cl}: 1.01,1.31)$ (Table 5$)$. Other variables that were found to be significantly associated at bivariate level were not significant predictors of postoperative delirium. 
Table 5

Predictors of postoperative delirium at multivariate level

\begin{tabular}{|c|c|c|}
\hline Variables & AOR (95\% Cl) & p-value \\
\hline Age & $1.15(1.01,1.31)$ & 0.042 \\
\hline \multicolumn{3}{|l|}{ Educational Status } \\
\hline Elementary and Junior & Reference & \\
\hline Illiterate & * & - \\
\hline Secondary and above & * & - \\
\hline \multicolumn{3}{|l|}{ Marital Status } \\
\hline Married & Reference & \\
\hline Single & $1.59(0.27,9.31)$ & 0.605 \\
\hline \multicolumn{3}{|l|}{ POP } \\
\hline Moderate to severe & Reference & \\
\hline Mild Pain & $1.34(0.22,8.33)$ & 0.754 \\
\hline No pain & $0.08(0.01,1.15)$ & 0.063 \\
\hline \multicolumn{3}{|l|}{ Cognitive Impairment } \\
\hline Normal & Reference & \\
\hline Mild & $1.52(0.18,12.72)$ & 0.702 \\
\hline Moderate to severe & $4.03(0.37,43.67)$ & 0.252 \\
\hline
\end{tabular}

\section{Discussion}

POD remains one of the most common, yet least reported, complications after surgery, especially in elderly (Dyer CB, Ashton CM, \& Teasdale TA, 2015). This study was envisioned to address the impact of spinal anesthesia on postoperative delirium in elderly patients in the National Referral Hospitals.

This study showed that the prevalence of POD after spinal anesthesia in elderly patients aged 65 years and above was $10.9 \%$. The overall prevalence of this study was supported by the study done in Italy over 351 participants out of which 47 (13.2\%) had POD (Ansaloni, Catena, Chattat, \& Fortuna, 2010). Almost similar finding was reported in the study carried out in China that prevalence of POD was $7.8 \%$.

However, the incidence rate of POD can vary from study to study, and this variety seems to be based on the diagnostic methods used by each study. One study reported that the prevalence of POD, using DSM-V, 
after total knee arthroplasty was 6.0\% (Kim, Kim, Kim, Kim, \& Lee, 2018). Another study done in Albania confirmed the incidence of postoperative delirium shows a higher rate $(26 \%)$. This was done for those patients who underwent surgery for TURP by using DRS and CAM tools. The current study done in Turkey investigated the incidence of delirium in elderly patients who performed orthopedic surgery was $15 \%$ using DRS and MMSE method (Ozbas et al., 2018). In this study diagnosis was limited to CAM checklist only.

In this study we found that age was significantly and positively associated with delirium on multivariate analysis. This is may be due to the fact that delirium is common in elderly since aging is more susceptible physiologic compensatory capability to adjust to the physical stress of surgery. The change in the content of central neurotransmitters such as acetylcholine, norepinephrine, epinephrine, and GABA are an important cause of delirium. Previous studies have also demonstrated that advanced age is a consistent, well-established risk factor for the development of delirium (Xue, Wu, Wang, Tu, \& Wang, 2016). This was also found as an overlapping risk factor in a review of 80 primary data collection studies (Dyer, Ashton, \& Teasdale, 1995).

Previous studies showed that the occurrence rate of POD increase by $2 \%$ when the age of the patient increases by one year (Wang et al., 2018). Further support for our study, found that a significant relationship between advanced age and had a cognitive impairment (Ozbas et al., 2018) and they conclude increasing in age found to be the most significant predictor to cause POD in elderly patients. Consistent with previous reports, our study demonstrate that age is the independent risk factor of POD and for unit increase in age, the odds of delirium was found to increase by 1.19 times (AOR $=1.15,95 \%$ Cl: $1.01,1.31)$.

In a study done by Ozbas et al., (2018) postoperative cognitive impairment in elderly patients is reported to be $28.1 \%-30.2 \%$. In this study, we found the incidence of delirium to be higher in patients with preoperative cognitive impairment whose scores from moderate to severe MMSE. This result were backed up by the study done in Italy in which they found preoperative cognitive impairment was one of the independent variable in association with POD in elderly patients (Ansaloni, Catena, Chattat, \& Fortuna, 2010). Different literatures also show the association was significantly higher in the delirious patients (Kim, Kim, Kim, Kim \& Lee, 2018, and Inouye et al., 2007). Increased rate of delirium is attributable to the worsen effect of aging in cognitive impairment and related problems. Contrary to this finding, other study concluded that cognitive impairment was not significantly associated in the incidence of POD (Xue, Wu, Wang, Tu, \& Wang, 2016).

POP is also known to be an important risk factor for POD (Kim, Kim, Kim, Kim, \& Lee, 2018). Recognizing the predisposing factors aids the clinician in early identification of patients at risk for delirium, understanding the precipitating risk factors allows for the development of strategies targeted at minimizing the occurrence of delirium. POP is one of the significant and potentially modifiable factor which is particularly important for the anaesthetist to consider in managing patients at risk for POD. A study done by Ozbas and his followers (2018) clearly indicate that POP is associated with the high 
incidence of delirium and shows higher rate patients with moderate to severe pain score. This finding is in consistent with our study that POP has an association with the incidence of POD.

In this study Some variables like gender, occupational status, type of surgery, duration of surgery, drug administered intraoperative, blood loss, ASA classification were not significantly associated risk factors.

Certain studies have found that delirium incidence is higher in male patients. Similarly male gender was found to be a risk factor for delirium (Chu, et al., 2016). On the contrary, certain other studies have shown no significant association between gender and delirium (Ozbas et al., 2018). Similar to our findings we found no association with gender.

ASA classification and blood loss were found to be as an associated factor in those aged participants (Wang, et al., 2018). But this study opposes this finding that we did find no correlation as the indicative risk factor in the incidence of POD. This was supported by Xue, Wu, Wang, Tu, \& Wang (2016) that they found no relationship between associated risk factor and ASA classification.

Comparing the drug administered intraoperative with other studies, it was found out that there is no association with POD. This can be due to low rate of intraoperative drug administered during the study period. Likewise a study by Xue, Wu, Wang, Tu \& Wang (2016) reported no association between perioperative medication and the incidence of POD. However, a study by Mekonen, Mihretie, Assefa, \&Fekadu (2015), found the odds of participants with poly therapy to had delirium were 2.4 times the odds of those without poly therapy. Moreover, those participants with benzodiazepine exposure were found to be 11.3 times more likely to had delirium as compared with those who were not exposed.

Even though we found no correlation among type of surgery and incidence of POD, a lot of literatures compete against this and found similar results in the incidence of POD. A meta-analysis of five studies showed that likelihood of delirium increased in patients who underwent total hip prosthesis surgery (Yang, et al., 2017). This findings supported by Ozbas et al., (2018), which shows a higher rate of incidence in elderly participants undergoing spinal anesthesia in hip surgery. Other study done in urological surgery, found a definite correlation with the incidence of POD (Matsuki, et al., 2017).

Finally, it can be stated that being an old aged participant by itself have many physiological and psychological deteriorations. Anticipating the possible contributing factors and planning to control them is the priority. As prevention is better than facing the situation after occurrences, focusing on the possible contributing elements is vital. It is undeniably true that postoperative delirium can be seen even after days of surgery.

\section{Limitation Of The Study}

This study was conducted in volunteer participants for short period of time and recognizing those participants who develop postoperative delirium after one week or two weeks was difficult. Had there been enough funding, it would have been done for extended period of time. 


\section{Conclusion}

In this study age of the participants showed to have a significant risk factor for the development of postoperative delirium. Gender, educational status, marital status, occupational status, type of surgery, duration of surgery, American Society of Anesthesiology classification, postoperative pain, drug administered intraoperative, blood loss and MMSE score did not significantly correlate with the occurrence of POD.

Therefore the identified predictor can be used to identify patients at increased risk for POD, and it provides an opportunity for effective intervention.

Early diagnosing and identification of delirium is important to prevent and manage the problem properly. Health care workers should identify patients who are at a high risk for developing delirium, and should develop appropriate approaches.

\section{Abbreviations}

AGS: American Geriatric Society, AOR: Adjusted Odds Ratio, ASA: American Society of Anesthesiologist, CAM: Confusion Assessment Method, Cl: Confidence Interval, COR: Crude Odds Ratio, DM: Diabetes Mellitus, DRS: Delirium Rating Scale, DSM-III-R: Diagnostic and Statistical Manual of Mental Disorder Revision 3, DSM-IV: Diagnostic and Statistical manual of Mental Disorder $4^{\text {th }}$ edition, HNRH: Halibet National Referral Hospital, ICU: Intensive Care Unit, ICD-10: International Classification of Disease $10^{\text {th }}$ Edition, IQR: Inter Quartile Range, MMSE: Mini Mental State Examination, MOH: Ministry of Health, VAS: Visual Analogue Scale, ACHS: Asmara college of Health Sciences, OMSNRH: Orotta Medical Surgical National Referral Hospital, POCD: Post-Operative Cognitive Dysfunction, POD: Post-Operative Delirium, POP: Post-Operative Pain, RASS: Richmond Agitation Sedation Scale, SA: Spinal Anesthesia, SD: Standard Deviation, SPSS: Statistical Package for Social Sciences, TURP: Transurethral Resection of Prostate

\section{Declarations}

\section{Ethical approval and consent to participate}

Ethical clearance was obtained from the ACHS ethical committee and $\mathrm{MOH}$ branch of research and ethical issues. Communication with hospital administration was made through formal letter obtained from ACHS. After the purpose of the study was explained, informed written consent was obtained from each study participants. Confidentiality was maintained by making the data collection procedure anonymous. Participation was on voluntary basis and the participants had the right to decline from the study at any time. For participants who were delirious during the study, it was made sure that a good control of their condition was taken and communication about their condition was done with either their respective health care providers or the family members. 


\section{Acknowledgement}

The authors would like to forward their gratitude to Mr. Eyasu Habte, for his meticulous contribution especially in the statistical aspect of the study and also for his support, comment and encouragement. The authors are also grateful to Dr. Gidey Ghebreyohannes, Head of school of nursing, ACHS research and ethical committee and also to the ministry of health for helping in approving this study. Finally the deepest gratitude goes to all the participants for their cooperation and support.

\section{Funding}

Not Applicable

\section{Availability of data and raw materials}

All the data collected from the volunteer participants are kept properly and can be retrieved if needed.

\section{Author's contributions}

Michael Beraki involved in the manuscript writing and processing of all the data. Yonatan Mehari involved in the restructuring and analysis of the data. Ariam, Habtom and Natsinet involved in data collection, refining the data entered and draft writing of the raw data entered. All the authors read and approved the manuscript.

\section{Consent for publication}

Not applicable.

\section{Competing interest}

No conflict of interest

\section{Publisher's note}

Not applicable

\section{Contributor information}

Michael Beraki, Email: mikoberaki88@gmail.com

Yonatan Mehari, Email: yonimer2@gmail.com

Ariam Tsegai, Email: aruioveu8g@gmail.com

Habtom Tareke, Email: habtegga@gmail.com

Natsinet Yacob, Email: natsiyacob@gmail.com 


\section{References}

American Geriatrics Society Expert Panel on Postoperative Delirium in Older Adults.Postoperative delirium in older adults: best practice statement from the American Geriatric Society. (2015). J Am Coll Surg, 13648.

Androsova, G., Krause, R., Winterer, G., \& Schneider, R. (2015). Biomarkers of postoperative delirium and cognitive dysfunction. Front. Aging Neurosci., p. 7:112. doi: 10.3389/fnagi.2015.00112.

Ansaloni, L., Catena, F., Chattat, R., \& Fortuna, D. (2010). Risk factors and incidence of postoperative delirium in elderly patients after elective and emergency surgery. British Journal of Surgery, 97(2):273280.doi:10.1002/bjs.6843.PubMed.

Bryson, G. (n.d.). Methods ans Madness: agitation, delirium. and postoperative cognitive dysfunction. Can J Anaesth.

Celsus AC. (1935). On Medicine. Harvard University Press.

Chu, C., Liang, C., Chou, M., Lin, Y., Hsu, C., \& Chou, P. (2016). Short-Form mini nutritional assessment as a useful method of predicting undergoing orthopedic surgery. Gen Hosp Psychiatry, pp. 38: 15-20.

Dyer CB, Ashton CM, \& Teasdale TA. (2015). Post operative delirium. A review of 80 primary datacollection studies. Arch Intern Med, pp. 115: 461-465.

Dyer, C., Ashton, C., \& Teasdale, T. (1995). Postoperative delirium. A review of 80- primary data collection studies. Arch Intern Med, pp. 155(5): 461-5.

Fitzpatrick, S., \& Owen, K. (2018, August 7). Postoperative Cognitive Disorders: Postoperative Delirium and Postoperative Cognitive Dysfunction. ANAESTHESIA TUTORIAL OF THE WEEK.

Gani, H., Pritti, P., Naco, M., Domi, R., Beqiri, V., Torba, D., \& Tare, R. (2012). The incidence of postoperative delirium in elderly patients undergoing urologic surgery. An International Journal of Anesthesiology, Pain Management, Intensive Care \& Resuscitation, 16(3):262-265.

Green, N. H., Attix, D. K., Weldon, B. C., Smith, P. J., McDonagh, D. L., \& Monk, T. G. (2009). Measures of executive function and depression identify patients at risk for postoperative delirium. Anesthesiology, 110.788-795. doi:10.1097/aln.0b013e31819b5ba6.

Grover, S., \& Kate, N. (2012). Assessment scales for delirium:A review. World Journal of Psychiatry, 2(4):58-70.doi: 10.5498/wjp.v2.i4.58.

Guo, Y., Jia, P., Zhang, J., Wang, X., Jiang, H., \& Jiang, W. (2016). Prevalence and risk factors of postoperative delirium in elderly hip fracture patients. Journal of International Medical Research, 44(2):317-327. doi:10.1177/0300060515624936. 
Inouye SK, e. a. (2007). Risk factors for delirium at discharge:development and validation of a predictive model. Arch Intern Med.

Inouye, S. K., Westendorp, R. G., \& Saczynski, J. S. (2013). Lancet. Retrieved from thelancet.com: http://dx.doi.org/10.1016/S0140-6736(13)6088-1

Inouye, S. K., Zhang, Y., Jones, R. N., kiely, D. K., Yang, F., \& Marcantonio, E. R. (2007). Risk factors for delirium at discharge: development and validation of a predictive model. Arch Intern Med, 167(13):14061413.[PubMed].

Inouye, S., Westendorp, R., \& Saczynski, J. (2015). Delirium in elderly people. Lancet, pp. pp.383:911-922.

Inouye, S., Westendorp, R., \& Saczynski, J. (2015). Delirium in elderly people . Lancet, pp. 383:911-922.

Kim, S.-w., Kim, N., Kim, J., Kim, K.-M., \& Lee, S. (2018). Risk factors for postoperative delirium following total knee arthroplasty in elderly patients. Science Central Journals, Anesth Pain Med 2018;13(2):143-148. doi: https://doi.org/10.17085/apm.2018.13.2.143.

Kotekar, N., Kuruvilla, C. S., \& Murthy, V. (2014). Post-operative cognitive dysfunction in the elderly:A Prospective clinical study. Indian Journal of Anesthesia, 58(3):263-268.

Liu, P., Li, Y., Wang, X., Zou, X., Zhang, D., \& Wang, D. (2013). High serum interleukin-6 level is associated with increased risk of delirium in elderly patients after noncardiac surgery: a prospective cohort study. Chin. Med. J.(Engl), 126,3621-3627. doi: 10.3716/cma.j.issn.0366-6999.20130211.

Matsuki, M., Takahashi, A., Inoue, R., Hotta, H., Itoh, N., Taguchi, K., \& Kato, R. (2017). Incidence and risk factors of postoperative delirium in elderly patients undergoing urological surgery:a multi-institutional prospective study. SAPPORO MEDICAL UNIVERSITY UROLOGIC ONCOLOGY CONSORTIUM, p. DOI: 10.3252/pso.eu.SIOG2017.2017.

McAlpine, J. N., Hodgson, E. J., Abramowitz, S., Richman, S. M., Su, Y., Kelly, M. G., . . Schwartz, P. E. (2008, May). Gynecologic Oncology. 109(2), pp. 296-302. https://doi.org/10.1016/j.ygyno.2008.02.016.

Mekonen, T., Mihretie, G., Assefa, D., \& Fekadu, W. (2015, January). Magnitude and Associated Factors of Delirium among Hospitalized Patients, Ethiopia:A Cross Sectional Study. Journal of Psychiatry, 18(3), 18:3.http://dx.doi.org/10.4172/psychiatry.1000267.

Morandi, A., Pandharipande, P., Trabucchi, M., Rozzini, R., Mistraletti, G., Trompeo, A., . . Gattinoni, L. (2008). Understanding international differences in terminology for delirium and other types of acute brain dysfunction in critically ill patients. Intensive Care Med, pp. 34(10):1907-1915.

Ozbas, A., AK, E. S., Cavdar, I., Akyuz, N., Findik, U. Y., \& Kutlu, F. Y. (2018). Determining the incidence of postoperative delirium in elderly patients who undergo orthopaedic surgical interventions in Turkey. Journal Of Pakistan Medical Association. 
Penninx BW, Guralnik JM, Onder G, Ferrucci L, Wallace RB, \& Pahor M. (2003). Anemia and decline in physical performance among older persons . Am J Med, 115: 104-10.

Persson, M., Olofsson, B., Stenvall, M., \& Karlsson, S. (2007, June). Postoperative delirium in old patients with femoral neck fracture: A ramdomized intervention study. Aging clinical and experimental research, pp. 19(3):178-86. doi:10.1007/BF03324687.

Postoperative Delirium in Older Adults. (2015). American Geriatrics Society, 220(2), p. http://dx.doi.org/10.1016/j.jamcollsurg.2014.10.019.

Radtke, F., Franck, M., Hagemann, L., Seeling, M., Wernecke, S., \& Spies, C. (2010). Risk factors for inadequate emergence after anesthesia: emergence delirium and hypoactive emergence. Minerva Anestesiol, pp. 76(6):394-403.

Reddy, S. V., Irkal, J. N., \& Srinivasamurthy, A. (2017). Postoperative delirium in elderly citizens and current practice. Journal of Anaesthesiology Clinical Pharmacology, 33(3), 33:291-9. DOI 10.4103/JOACP_180_16.

Rengel, K. F., Pandharipande, P. P., \& Hughes, C. G. (2018). Postoperative delirium. Presse Med., p. https://doi.org/10.1016/j.lpm.2018.03.012.

Robinson, T. N., Raeburn, C. D., Tran, Z. V., Angles, E. M., Brenner, L. A., \& Moss, M. (2009). Posoperative delirium in the elderly: risk factors and out comes. Ann. surg, 249,173-178. doi:10.1097/SLA.0B013e31818e4776.

Robinson, T. N., Raeburn, C. D., Tran, Z. V., Angles, E. M., Brenner, L. A., \& Moss, M. (n.d.). POSTOPERAT. Rudolph JL, \& Marcantonio ER. (2011). Postoperative delirium: acute change with long-term implications. Anesth Analg , pp. 112:1202-11.

Rudolph, J. L., Marcantonio, E. R., Culley, D. J., Silverstein, J. H., Rasmussen, L. S., Crosby, G. J., \& Inouye, s. k. (2008, September). Delirium is associated with early postoperative cognitive dysfunction. Author Manuscript, pp. 63(9):941-947.doi:10.1111/j.1365-2044.2008.05523.x.

Steinmetz, J., Christensen, K. B., Lund, T., Lohse, N., Rasmussen, L. S., \& ISPOCD Group. (2009). Long-term consequences of postoperative cognitive dysfunction. Anesthesiology, 110, 548-555. doi:

10.1097/ALN.0b013e318195b569.

Tintinalli, J. E., Kelen, G. D., \& Stapezynski, J. S. (2004). Emergency Medicine: a comprehensive study guide (6th ed.). (A. Seils, N. Fernando, \& M. Watt, Eds.) United States of America: McGraw-Hill.

Varro, M. (1938). On the Latin Language. Harvard University Press. 
Vijayakumar, B., Elango, P., \& Ganessan, R. (2014). Post-operative delirium in elderly patients. Indian Journal Anaesthesia, 58(3):251-256.doi: 10.4103/0019-5049.135026.

Wang, C.-g., Qin, Y.-f., Wan, X., Song, L.-C., Li, Z.-j., \& Li, H. (2018). Incidence and riskfactors of postoperative delirium in the elderly patients with hip fracture. Journal of Orthopaedic Surgery and Research, 13:186.dio: 10.1186/s13018-018-0897-8.

Whitlock, E. L., Vannucci, A., \& Avidan, M. S. (2011, April). Postoperative Delirium. Minerva Anestesiologica, pp. 77(4):448-456.

Xue, P., Wu, Z., Wang, K., Tu, C., \& Wang, X. (2016, January 12). Incidence and risk factors of postoperative delirium in elderly patients undergoing transurethral resection of prostate: a prospective cohort study. Journal of Neuropsychiatric Disease and Treatment, 12, 137-142. doi https://doi.org/10.2147/NDT.S97249.

Yang, Y., Zhao, X., Dong, T., Yang, Z., Zhang, Q., \& Zhang, Y. (2017). Risk factors for postoperative delirium following hip fracture repair in elderly patients: a systematic review and meta-analysis. Aging Clin Exp Res, pp. 29: 115-26.

Yasayacak, A., \& Eker, F. (2012). Determining delirium and risk factors of patients in cardiovascular surgery intensive care unit. Turkish Journal Thoracic, 20:265-74.

Yu, D., Chai, W., Sun, X., \& Yao, L. (2010). Emergence agitation in adults: risk factors in 2000 patients. Can $J$ Anaesth.

Zieschang T, Wolf M, Vellappallil T, Uhlmann L, Oster P, \& Kopf D. (2016). The association of hyponatremia, risk of confusional state, and mortality. Dtsch Arzteb/ Int, pp. 113: 855-62.

\section{Figures}




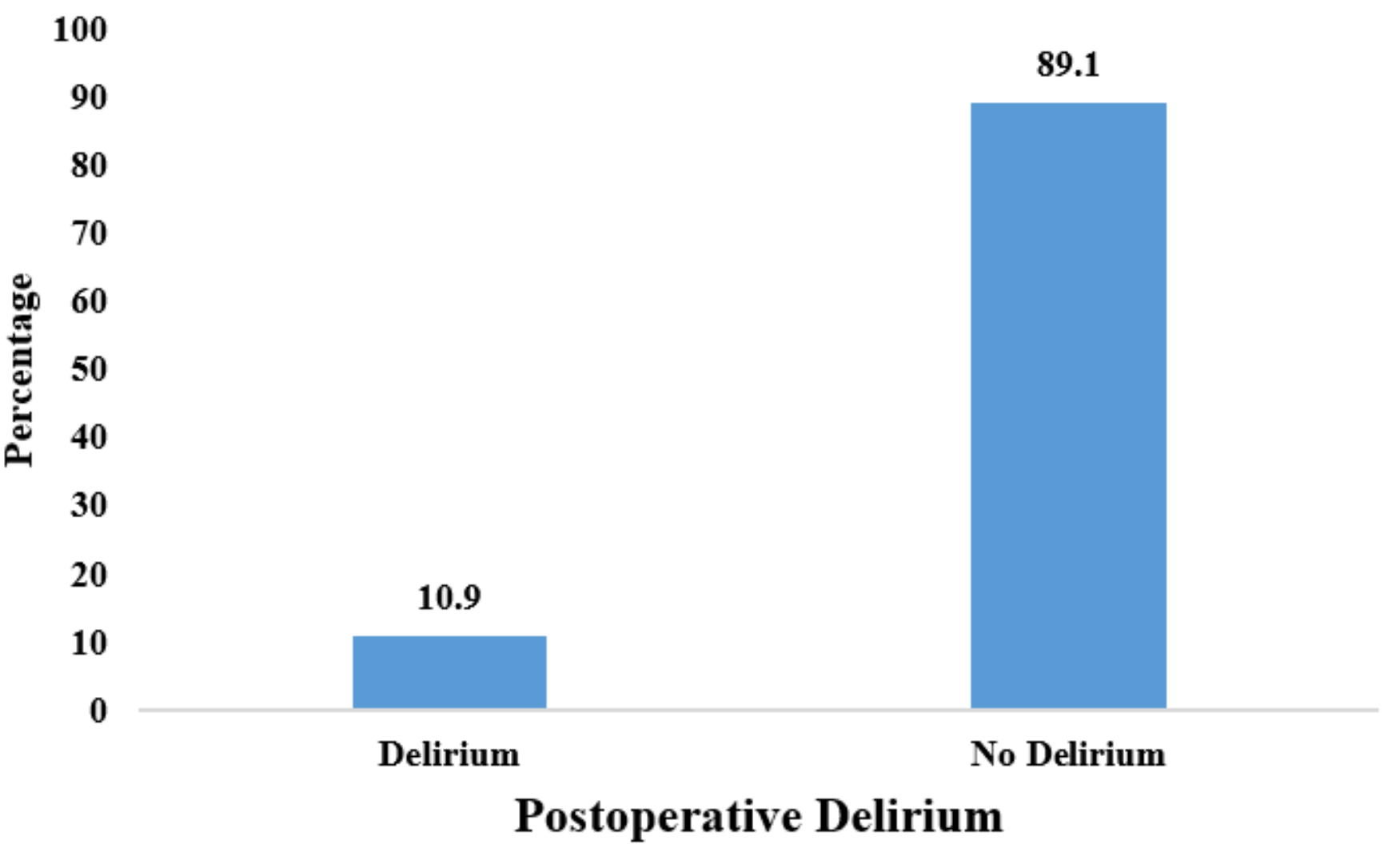

Figure 1

Incidence of postoperative delirium 